\title{
Clinical features and outcome of septic arthritis in a single UK Health District 1982-1991
}

\author{
V C Weston, A C Jones, N Bradbury, F Fawthrop, M Doherty
}

\begin{abstract}
Aims-To determine the clinical features of a large number of unselected UK hospital patients with confirmed septic arthritis and to determine those features associated with a poor outcome.

Study design-Retrospective, case-note survey.

Setting-A single English Health District. Patients-All patients admitted to hospital in Nottingham during the period 1 January 1982 to 31 December 1991 with confirmed septic arthritis were included. Outcome measures-Death, osteomyelitis and recorded functional impairment.

Results-The spectrum of causative organisms remains similar to that seen in previous studies with the Gram positive organisms Staphylococcus aureus and Streptococci responsible for $74 \%$ of cases, gonococcal infections though were less common. Culture of joint aspirates and or blood were positive in $82 \%$ of cases, with the Gram stain demonstrating the causative organism in $50 \%$ of cases. Pre-existing joint disease was evident in $35 \%$ of cases. The mortality remains high at $11.5 \%$ with a significant additional morbidity of $31.6 \%$. Multivariate analysis suggests that important predictors of death are: confusion at presentation, age $\geqslant 65$ years, multiple joint sepsis or involvement of the elbow joint, and of morbidity are: age $\geqslant 65$ years, diabetes mellitus, open surgical drainage, and Gram positive infections other than $S$ aureus.
\end{abstract}

Conclusions-Septic arthritis continues to be associated with a considerable degree of morbidity and mortality. These results confirm the importance of obtaining synovial fluid and blood for culture before starting antimicrobial treatment. The apparent poorer outcome found with surgical intervention is in line with some previous suggestions but should be interpreted with caution in light of the retrospective nature of this study.

(Ann Rheum Dis 1999;58:214-219)

and PHLS

V C Weston

Queen's Medical Centre, Nottingham

Correspondence to: Dr V C Weston, PHLS, University Hospital, Queen's Medical Centre, Derby Road, Nottingham NG7 2UH.

Accepted for publication 14 January 1999.

Septic arthritis remains an important infection, associated with both significant mortality and morbidity. ${ }^{1-7}$ However, many studies of its clinical features have mainly been small or concentrated on selected patient populations (adults, children or surgical infections). Although secular trends in the nature of the disease, both in terms of the risk factors involved and the nature of the pathogens implicated, have been suggested, no recent large scale sys- tematic studies of septic arthritis have been reported in the United Kingdom. ${ }^{12}$ Furthermore, systematic data on the causative pathogens in septic arthritis are not routinely collated by many microbiology departments or by the Communicable Disease Surveillance Centre (CDSC). ${ }^{7}$ This makes development of appropriate treatment and management protocols problematic. ${ }^{8}$

This study was undertaken to determine the spectrum of septic arthritis seen at two major teaching hospitals serving a single UK Health District (population 632000 ) over a 10 year period. The study was designed to be as comprehensive as possible and used multiple methods of patient ascertainment.

\section{Methods}

CASE DEFINITION

We used the same case definition criteria as the last major United Kingdom surveys although chose not to specifically exclude tuberculosis or sepsis related to joint surgery. ${ }^{12}$

The essential features of this definition are (table 1):

Group 1 Microbial pathogen identified in, or isolated from synovial fluid or joint tissues

Group 2 Typical features of septic arthritis with pathogen isolated from other source(s), for example, blood

Group 3 Pus obtained from the joint but joint culture sterile because of previous administration of antibiotics

Group 4 Definite radiological or postmortem diagnosis of septic arthritis

ASCERTAINMENT

The major source of patient ascertainment was the Hospital Activity Index (HAI) for the two major Nottingham Hospitals, (City Hospital Trust and University Hospital Trust) for the period 1 January 1982 to 31 December 1991. Patients coded as having pyogenic arthritis, gonococcal arthritis, tuberculous arthritis and arthritis in association with salmonellas and streptococci were identified. To maximise the number of cases identified additional sources of ascertainment were also used. These included: the ward admission book of the
Table 1 Diagnostic criteria for septic arthritis that were fulfilled $^{12}$

\begin{tabular}{ll}
\hline Criteria fulfilled & $\begin{array}{l}\text { Number of } \\
\text { patients }\end{array}$ \\
\hline Group 1: pathogen from joint (Gram stain & \\
positive and/or culture positive) & 169 \\
Group 2: pathogen from other source & 32 \\
Group 3: prior antibiotics & 38 \\
Group 4: postmortem diagnosis & 4 \\
\hline
\end{tabular}


rheumatology ward (1 January 1982 to 31 December 1991); the microbiology department computer records for all positive synovial fluid culture results (1 January 1991 to 31 December 1991); the orthopaedic theatre book (1 January 1991 to 31 December 1991); notifications of bone and joint infections with bacteraemia to the Communicable Disease Surveillance Centre (CDSC) (1 January 1988 to 31 December 1991); and the diagnostic index of two rheumatology consultants. Septic arthritis was defined by the criteria of Newman ${ }^{1}$ as modified by Cooper and Cawley ${ }^{2}$ and outlined above.

NOTE SURVEY

All patient notes were examined in a structured fashion using a standard proforma. Record was taken of: patient age and sex at presentation; delay in presentation; method of referral to hospital; specialty referred to; previous history of joint disease; history of recent trauma or instrumentation; underlying immunosuppression either because of drugs and/or disease; maximum fever during the first week of admission; white blood cell count and differential, erythrocyte sedimentation rate (ESR), $\mathrm{C}$ reactive protein (CRP), serum urea and creatinine; dates of hospital stay; results of microbiological testing; details of medical and surgical treatment; and assessment of functional outcome as recorded in the notes. Delay in presentation was defined as the interval, in days, between the onset of symptoms attributable to septic arthritis and presentation of the patient to medical services. Delay in diagnosis is the interval from onset of symptoms to the specific diagnosis of septic arthritis being considered. Sepsis was considered to have contributed to death when no other specific cause, for example, terminal malignancy was apparent from the notes.

Appropriateness and adequacy of antibiotic dose and duration was determined from the limited published data on recommended drug doses for bone and joint infections ${ }^{9-11}$ and took into account the patient's age and previously described risk factors (for example, immunosuppression, prosthetic material, rheumatoid disease). In the absence of a generally agreed consensus on antibiotic treatment duration a relaxed definition was used to define adequate dose duration. For intravenous antibiotics an adequate course was defined as an appropriate dose given for at least seven days in adults, three days in a child or until death. An adequate oral duration was similarly defined as an adequate dose given for at least 14 days or until death.

STATISTICAL ANALYSES

Multiple logistic regression analysis (SPSS) was used to determine risk factors for outcome. Mortality was used as a dependent variable versus all survivors. Recorded poor outcome and osteomyelitis were analysed compared with those patients with a recorded good outcome. Logistic regression was used (SPSS) with all potential risk factors entered into the model. These included: age (in the case of
Table 2 Organisms identified as causes of septic arthritis

\begin{tabular}{lll}
\hline Organism & $\begin{array}{l}\text { Number of } \\
\text { cases }\end{array}$ & $\%$ \\
\hline S aureus & 108 & 54 \\
Streptococci & 36 & 18 \\
$\quad$-haemolytic streptococci & 24 & \\
$\quad$ S pneumoniae & 11 & \\
Other streptococci & 1 & 1.5 \\
Enterococci & 3 & 7.5 \\
Coliform bacilli & 15 & 7.5 \\
H influenzae type b & 15 & 4.5 \\
Neisseria spp & 9 & 3 \\
Mixed infection & 6 & 0.5 \\
M tuberculosis & 1 & 3 \\
Other & 6 & \\
\hline
\end{tabular}

mortality age $\geqslant 65$; in the case of morbidity entered as the age groups $\leqslant 4,5-15,16-64$, $\geqslant 65$ years); confusion; open surgery; arthroscopic surgery; delay ( $\leqslant 3$ days, $>3$ days); diabetes mellitus; joint involvement (hip, knee, shoulder, elbow, other, multiple); organism (no organism identified, Staphylococcus aureus, streptococci, other Gram positive organisms, Gram negative organisms (other than Haemophilus influenzae), Haemophilus influenzae; presence of prosthetic material; closed (percutaneous) needle drainage; sex; and concurrent oral corticosteroids. In the case of multiple organisms the patient was classified according to the predominant organism. In three patients the culture was $S$ aureus and Group A streptococci and they were analysed as $S$ aureus; two patients had mixed Gram negative organisms and the final patient had mixed Gram positive organisms and was included in the other Gram positive group.

\section{Results}

ASCERTAINMENT

Four hundred and seventy six possible cases of septic arthritis were identified of which 462 medical notes were traceable and examined. The majority of potential cases (371) were identified using the HAI. Comparison with other sources of information not all of which were available for the whole 10 year period produces an estimate suggesting that using the HAI would have missed $35 \%$ of all cases. From these 239 patients with 243 separate episodes of sepsis were identified as fulfilling the criteria for septic arthritis. The numbers fulfilling the various diagnostic criteria are tabulated (table 1). One patient was transferred to a private hospital and their final outcome is unknown and thus 242 patients were evaluable for the outcome analysis.

PATHOGENS AND JOINTS INVOLVED

Causative organisms were cultured in 199 cases $(82 \%)$ these are listed (table 2$)$. In common with previous studies $S$ aureus was the commonest pathogen in all age groups but unlike earlier surveys H influenzae and Neisseria gonorrhoeae were uncommon. As expected $95 \%$ of $S$ aureus isolates were penicillin resistant. The different organisms found in the different risk groups are tabulated (table 3). Gram negative infections were uncommon but more likely in patients with diabetes mellitus. $S$ aureus was more common in those with prosthetic mate- 
Table 3 Prevalence of organisms in different risk groups (numbers in parentheses are percentages)

\begin{tabular}{llllll}
\hline & & & & & \\
& S aureus & $\begin{array}{l}\text { Streptococci (not } \\
\text { including enterococci) }\end{array}$ & $\begin{array}{l}\text { Gram } \\
\text { negative }\end{array}$ & H influenzae & $\begin{array}{l}\text { Tosith } \\
\text { positive } \\
\text { microbiology }\end{array}$ \\
\hline $\begin{array}{l}\text { Overall } \\
\text { Age (y) }\end{array}$ & $111(54)$ & $36(18)$ & $29(15)$ & $15(7.5)$ & 199 \\
$<5$ & $5(18)$ & $6(21)$ & $2(7)$ & $13(46)$ & 28 \\
$5-15$ & $12(63)$ & $5(26)$ & $2(11)$ & $0(0)$ & 19 \\
$16-64$ & $50(65)$ & $7(9)$ & $15(19)$ & $1(1)$ & 77 \\
$>65$ & $44(59)$ & $18(24)$ & $10(13)$ & $1(1)$ & 75 \\
Diabetes & $6(55)$ & $1(9)$ & $4(36.4)$ & $0(0.0)$ & 11 \\
Corticosteroid & $12(60)$ & $4(20)$ & $4(20.0)$ & $0(0.0)$ & 20 \\
RA & $23(70)$ & $5(15)$ & $4(12.1)$ & $0(0.0)$ & 33 \\
OA & $18(20)$ & $4(4)$ & $1(1.1)$ & $0(0.0)$ & 31 \\
Prosthetic material & $18(75)$ & $1(4)$ & $2(8.3)$ & $1(4.2)$ & 24 \\
\hline
\end{tabular}

Table 4 foint sites involved with septic arthritis

\begin{tabular}{lll}
\hline foint involved & Number & $\%$ \\
\hline Knee & 74 & 30.5 \\
Hip & 39 & 16.0 \\
Multiple joints & 36 & 14.8 \\
Elbow & 22 & 9.1 \\
Interphalangeal or metacarpophalangeal & 20 & 8.2 \\
Glenohumeral or acromioclavicular & 19 & 7.8 \\
Ankle or sub-talar & 15 & 6.2 \\
Wrist & 10 & 4.1 \\
Metatarsophalangeal & 5 & 2.1 \\
Sternoclavicular & 2 & 0.8 \\
Sacroiliac & 1 & 0.4 \\
\hline
\end{tabular}

Table 5 Potential risk factors for septic arthritis

\begin{tabular}{lll}
\hline Potential risk factor & Number & $\%$ \\
\hline Rheumatoid arthritis & 39 & 16 \\
Osteoarthritis & 37 & 15 \\
Other joint disease & 9 & 4 \\
Diabetes mellitus & 15 & 6 \\
Cytotoxic therapy & 4 & 2 \\
Oral corticosteroids & 25 & 10 \\
Intra-articular corticosteroids & 8 & 3 \\
Previous joint or local surgery & 26 & 11 \\
Recent trauma & 52 & 21 \\
$\quad$ Blunt & 18 & \\
Closed & 13 & \\
Open & 21 & \\
Underlying carcinoma & 8 & 3 \\
Upper respiratory tract infection & 15 & 6 \\
Skin ulceration & 27 & 11 \\
Other septic focus & 18 & 7 \\
No apparent risk factor & 54 & 22 \\
\hline
\end{tabular}

rial and patients with rheumatoid arthritis. $H$ influenzae was almost exclusively isolated in those less than 4 years old.

The joints involved are tabulated (table 4). The commonest joint involved was the knee

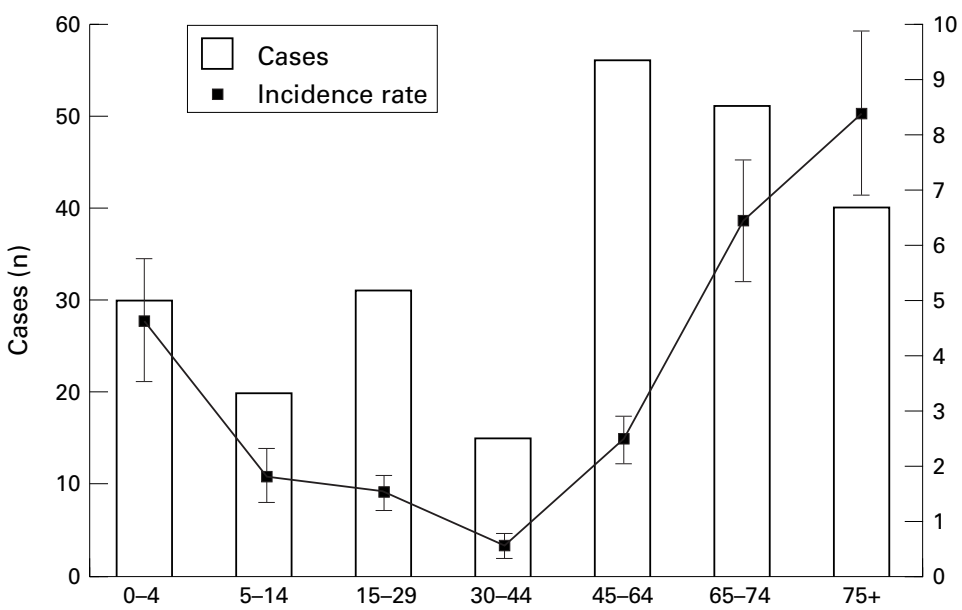

Figure 1 Age distribution of patients with septic arthritis.
Table 6 Specialty to which patient presented

\begin{tabular}{ll}
\hline Specialty at presentation & Number of cases \\
\hline Rheumatology & 42 \\
Orthopaedics & 131 \\
Health care of the elderly & 20 \\
Medicine & 34 \\
Accident and emergency & 8 \\
Other & 8
\end{tabular}

joint but it should be noted that septic arthritis presented in multiple joints in $15 \%$ of cases.

RISK FACTORS

The major potential risks factors for the development of septic arthritis are listed (table 5). Twenty two per cent of patients had no readily identifiable risk factor for septic arthritis. Previous joint disease was evident in only 35\% of cases; $65 \%$ of patients had previously apparently normal joints. Rheumatoid arthritis was extremely commonly seen (16\%) compared with its expected frequency in the population of approximately $1 \%$. Septic arthritis was found to be more common at the extremes of age (fig 1). Using estimates derived from only those cases resident in the Nottingham Health Authority (161 cases) the overall crude incidence rate was $2.6 / 100000$ person years $(95 \%$ confidence intervals 2.4, 2.8). Assuming this represents an under ascertainment of cases of $35 \%$ this suggests an overall incidence of 4 per 100000 person years. The sex incidence was approximately equal (male 2.59, female 2.65 ). The age specific incidence rate is also shown (fig 1).

DIAGNOSIS AND PRESENTATION

The median delay in presentation was three days, (interquartile range of 1-7 days). Forty eight per cent of patients were referred via their general practitioners and $41 \%$ via casualty. The majority of patients were referred to the orthopaedic and rheumatology specialties but a variety of specialties need to be aware of the diagnosis and its management (table 6). Delay in diagnosis often occurred with a mean value 9.7 days.

One hundred and sixty two patients (67\%) had a positive microbiological culture result from a joint aspirate; in $58(24 \%)$ the blood cultures were also positive. In an additional 22 patients $(9 \%)$, blood cultures were the only source of a positive microbiological diagnosis.

It is not possible to determine the sensitivity and specificity of the various microbiological tests in diagnosing septic arthritis because of the selective nature of this series. However, it is possible to determine the value of ancillary investigations. Fever was only present in 58\% of cases and the total white cell count was increased in only $50 \%$ of the 208 cases were it had been tested (based on age specific reference ranges, normal adult range 4-11.5 $\times$ $\left.10^{9} 1^{-1}\right)$. The ESR, performed in 138 patients was often only moderately increased and occasionally normal. In contrast the CRP (measured in 51 patients) was usually raised and greater than $100 \mathrm{mg} / \mathrm{ml}$ (normal $<20 \mathrm{mg} / \mathrm{ml}$ ). (fig 2). 
Table 7 Univariate analysis of risk factors for death in 242 patients with septic arthritis

\begin{tabular}{|c|c|c|c|c|c|c|}
\hline Risk & Number & $\begin{array}{l}\text { Mortality } \\
(\text { total }=29)\end{array}$ & $\begin{array}{l}\text { Mortality } \\
\%(12 \%)\end{array}$ & Odds & $95 \% C I$ & Significant \\
\hline Confusion & 23 & 8 & 35 & 5.03 & $1.91,13.25$ & 夫 \\
\hline Arthroscopy & 32 & 2 & 6 & 0.45 & $0.10,2.00$ & \\
\hline Female sex & 108 & 15 & 14 & 1.38 & $0.64,3.01$ & \\
\hline Oral corticosteroids & 24 & 4 & 17 & 1.54 & $0.49,4.88$ & \\
\hline Close & 155 & 24 & 15 & 3.00 & $1.10,8.19$ & * \\
\hline Delay $>3$ days & 115 & 16 & 14 & 1.42 & $0.65,3.09$ & \\
\hline Diabetes mellitus & 15 & 1 & 7 & 0.51 & $0.06,4.01$ & \\
\hline Open drainage & 124 & 4 & 3 & 0.12 & $0.04,0.37$ & $\star$ \\
\hline Prosthesis & 25 & 3 & 12 & 1.00 & $0.28,3.58$ & \\
\hline \multicolumn{7}{|l|}{ Age $(y)$} \\
\hline$\leqslant 64$ & 152 & 7 & 5 & & & \\
\hline$\geqslant 65$ & 68 & 22 & 32 & 6.7 & $2.56,18.23$ & $\star$ \\
\hline Joint (hip) & 39 & 6 & 15 & & & \\
\hline Knee & 74 & 12 & 16 & 1.06 & $0.33,3.54$ & \\
\hline Shoulder & 17 & 4 & 24 & 1.69 & $0.33,8.49$ & \\
\hline Elbow & 22 & 1 & 5 & 0.26 & $0.01,2.51$ & \\
\hline Other & 57 & 1 & 2 & 0.10 & $0.00,0.89$ & $\star$ \\
\hline Multiple & 33 & 5 & 15 & 0.98 & $0.23,4.18$ & \\
\hline Organism (nil) & 43 & 2 & 5 & & & \\
\hline$S$ aureus & 111 & 20 & 18 & 4.91 & $0.95,29.30$ & \\
\hline Streptococci & 36 & 3 & 8 & 1.86 & $0.23,17.14$ & \\
\hline Other gram positive & 8 & 2 & 25 & 6.83 & $0.54,90.40$ & \\
\hline Gram negative & 29 & 2 & 7 & 1.52 & $0.14,16.35$ & \\
\hline H influenzae & 15 & 0 & 0 & 0.00 & $0.00,12.54$ & \\
\hline
\end{tabular}

TREATMENT

Of 239 patients in whom data on initial antibiotic treatment were available an appropriate initial antibiotic was given in 207 (87\%). A total of 21 different antibiotic combinations were, however, used in initial treatment with the commonest being flucloxacillin and an aminopenicillin (52 patients), flucloxacillin and fusidic acid (47), flucloxacillin and benzylpenicillin (27), and flucloxacillin alone (26).

Of 233 patients in whom details of intravenous therapy were available the dose used was inadequate in $59(34 \%)$. With oral antibiotics 25 of $207(12 \%)$ of patients received an inadequate dose. The duration of treatment was very variable with a mean length of intravenous therapy and oral therapy of 10.2 days and 55.3 days respectively. Of 173 patients receiving adequate intravenous dose in whom the duration of treatment was known, an inadequate duration was observed in 24 $(14 \%)$. The figure for oral antibiotic duration was 13 of $179(7 \%)$.
OUTCOME

This series demonstrated that septic arthritis is associated with a significant mortality of $11.5 \%$; all but one of the 29 deaths being directly attributable to sepsis. The morbidity is also considerable at $31.6 \%$ (osteomyelitis $7.8 \%$; poor functional outcome in $23.8 \%$ ) and the average hospital inpatient bed stay was 26.7 days. Univariate risk factors (table 7 and table 8 ) and multivariate risk factors (table 9 and table 10) for death and morbidity are tabulated.

Univariate analysis suggests that confusion at presentation, percutaneous drainage, and age greater than 65 years were associated with increased mortality whereas open surgical drainage was associated with reduced mortality. Multivariate analysis suggested, however that confusion, age greater than 65 years and multiple or elbow joint involvement were independently associated with increased mortality whereas open drainage was associated with a reduced mortality.

With regard to morbidity, a delay in presentation of greater than three days, the presence of prosthetic material and both arthroscopic and open surgical drainage were associated with increased morbidity (poor function or osteomyelitis). Age less than 4 years was associated with a better outcome. On multivariate analysis, age greater than 65 years, diabetes mellitus, open surgical drainage and infection with Gram positive organisms other than $S$ aureus were independently associated with poor outcome whereas closed (percutaneous) drainage, age less than 4 years and infection with $H$ influenzae were associated with a better outcome.

As the number of patients in whom antibiotic data are available is variable the effect of antibiotic threatment on outcome has been analysed separately. The mortality was the same in those given inappropriate or appropriate initial treatment; $9 \%$ and $12 \%$ respectively ( $p>0.05$, Fisher's exact test). Similar results

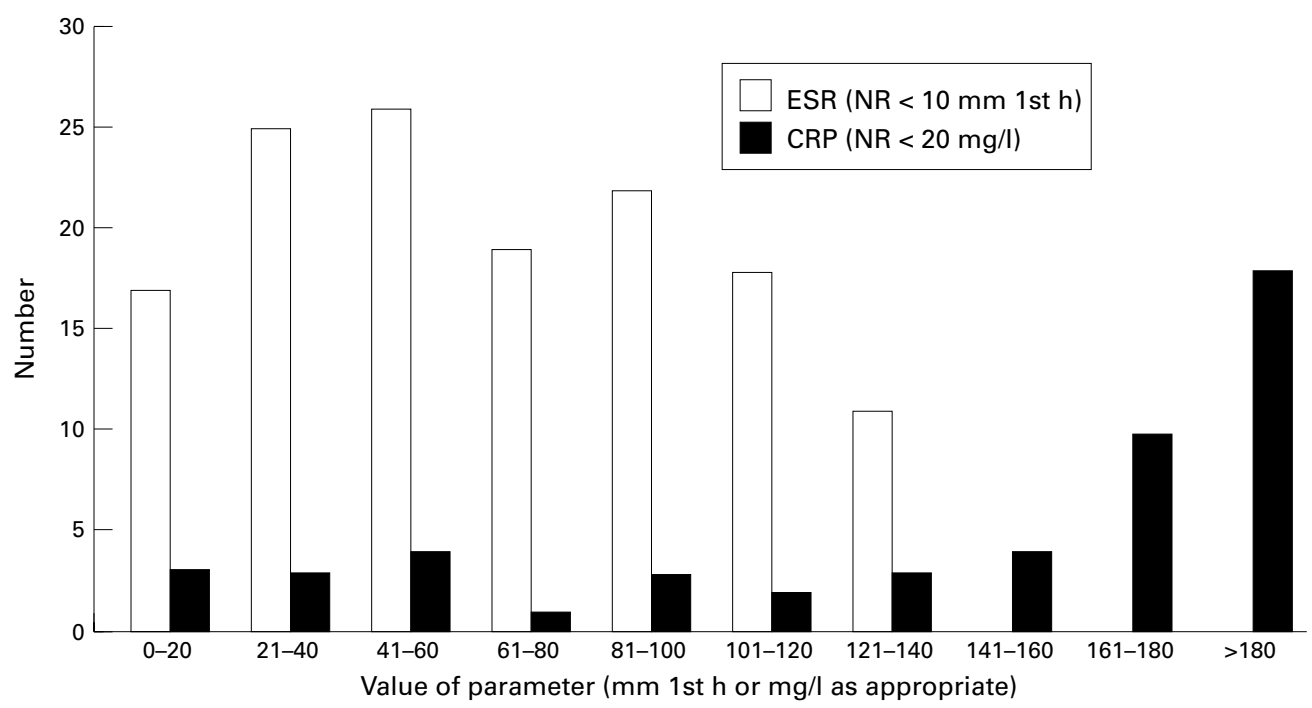

Figure 2 Distribution of ESR and CRP measurements in patients presenting with septic arthritis. Eight patients had an $E S R$ in the normal range $(<10 \mathrm{~mm} 1 \mathrm{st} h)$; three had a CRP within the normal range $(<20 \mathrm{mg} / \mathrm{ml})$. 
were observed for inappropriate and appropriate: dose of intravenous antibiotic, $10 \%$ and $10 \%(\mathrm{p}>0.05)$; dose of oral antibiotic, $4 \%$ and

Table 8 Univariate analysis for poor outcome (poor function or osteomyelitis) in 213 patients with septic arthritis

\begin{tabular}{|c|c|c|c|c|c|c|}
\hline Risk & Number & $\begin{array}{l}\text { Morbidity } \\
\text { (total }=76 \text { ) }\end{array}$ & $\begin{array}{l}\text { Morbidity } \\
\%(36 \%)\end{array}$ & Odds & $95 \% C I$ & Significant \\
\hline $\begin{array}{l}\text { Confusion at } \\
\text { presentation }\end{array}$ & 15 & 4 & $27 \%$ & 0.64 & $0.20,2.07$ & \\
\hline Arthroscopy & 30 & 16 & $53 \%$ & 2.34 & $1.07,5.12$ & $\star$ \\
\hline Female sex & 93 & 31 & $33 \%$ & 0.83 & $0.47,1.47$ & \\
\hline Oral corticosteroids & 20 & 9 & $45 \%$ & 1.54 & $0.61,3.90$ & \\
\hline Closed drainage & 131 & 76 & $58 \%$ & 0.56 & $0.32,1.00$ & $\star$ \\
\hline Delay $>3$ days & 99 & 43 & $43 \%$ & 1.88 & $1.07,3.32$ & $\star$ \\
\hline Diabetes mellitus & 14 & 8 & $57 \%$ & 2.57 & $0.86,7.70$ & \\
\hline Open drainage & 120 & 52 & $43 \%$ & 2.20 & $1.22,3.96$ & $\star$ \\
\hline Prosthesis & 22 & 15 & $68 \%$ & 4.57 & $1.77,11.78$ & $\star$ \\
\hline $\begin{array}{l}\text { Age }(y) \\
15-64\end{array}$ & 90 & 35 & $39 \%$ & & & \\
\hline$\leqslant 4$ & 30 & 2 & $7 \%$ & 0.11 & $0.02,0.53$ & $\star$ \\
\hline $5-14$ & 25 & 6 & $24 \%$ & 0.50 & $0.16,1.49$ & \\
\hline$\geqslant 65$ & 68 & 33 & $49 \%$ & 1.48 & $0.75,2.95$ & \\
\hline Joint (hip) & 33 & 9 & $27 \%$ & & & \\
\hline Knee & 62 & 22 & $35 \%$ & 1.47 & $0.53,4.11$ & \\
\hline Shoulder & 13 & 7 & $54 \%$ & 3.11 & $0.68,14.66$ & \\
\hline Elbow & 21 & 5 & $24 \%$ & 0.83 & $0.20,3.45$ & \\
\hline Other & 56 & 22 & $39 \%$ & 1.73 & $0.62,4.89$ & \\
\hline Multiple & 28 & 11 & $39 \%$ & 1.73 & $0.52,5.83$ & \\
\hline Organism (nil) & 41 & 12 & $29 \%$ & & & \\
\hline$S$ aureus & 91 & 42 & $46 \%$ & 2.07 & $0.88,4.93$ & \\
\hline Streptococci & 33 & 6 & $18 \%$ & 0.54 & $0.15,1.84$ & \\
\hline Other gram positive & 6 & 3 & $50 \%$ & 2.42 & $0.32,18.31$ & \\
\hline Gram negative & 27 & 12 & $44 \%$ & 1.93 & $0.62,6.05$ & \\
\hline H influenzae & 15 & 1 & $7 \%$ & 0.17 & $0.01,1.53$ & \\
\hline
\end{tabular}

Table 9 Multivariate analysis for death in 242 patients with septic arthritis

\begin{tabular}{llll}
\hline Risk & Odds ratio & $95 \% C I$ & \multirow{2}{*}{ Significance } \\
\hline Confusion at presentation & 3.26 & $1.77,5.99$ & $\star$ \\
Arthroscopy & 0.44 & $0.17,1.12$ & \\
Female sex & 0.83 & $0.48,1.45$ & \\
Oral corticosteroids & 1.26 & $0.57,2.78$ & \\
Closed drainage & 0.85 & $0.37,1.94$ & \\
Delay > 3 days & 1.20 & $0.92,1.56$ & \\
Diabetes mellitus & 0.29 & $0.08,1.03$ & $\star$ \\
Open drainage & 0.16 & $0.08,0.31$ & $\star$ \\
Prosthesis & 0.93 & $0.36,2.36$ & $\star$ \\
Age $\geqslant 65$ & 5.05 & $2.84,8.99$ & $\star$ \\
Knee & 1.51 & $0.80,2.83$ & $\star$ \\
Shoulder & 0.26 & $0.09,0.78$ & \\
Elbow & 2.01 & $1.22,3.31$ & \\
Other & 0.14 & $0.05,0.37$ & \\
Multiple & 2.37 & $1.30,4.35$ & \\
S aureus & 0.60 & $0.01,34.53$ & \\
Streptococci & 1.07 & $0.02,62.40$ & \\
Other gram positive & 5.79 & $0.11,318.68$ & \\
Gram negative & 13.73 & $0.23,834.06$ & \\
H influenzae & 1.01 & $0.02,59.29$ & \\
\hline
\end{tabular}

Table 10 Multivariate analysis for risk factors for poor outcome in 213 survivors of septic arthritis

\begin{tabular}{|c|c|c|c|}
\hline Risk & Odds ratio & $95 \% C I$ & Significance \\
\hline Confusion at persentation & 0.52 & $0.25,1.09$ & \\
\hline Arthroscopy & 1.72 & $0.96,3.09$ & \\
\hline Female sex & 0.91 & $0.61,1.35$ & \\
\hline Oral corticosteroids & 1.25 & $0.67,2.33$ & \\
\hline Closed drainage & 0.41 & $0.26,0.63$ & * \\
\hline Delay $>3$ days & 1.00 & $0.83,1.21$ & \\
\hline Diabetes mellitus & 2.71 & $1.41,5.22$ & $\star$ \\
\hline Open drainage & 3.74 & $2.47,5.67$ & * \\
\hline Prosthesis & 1.40 & $0.74,2.68$ & \\
\hline Age $\leqslant 4$ & 0.19 & $0.10,0.38$ & * \\
\hline Age 5-14 & 0.79 & $0.49,1.27$ & \\
\hline Age $\geqslant 65$ & 1.54 & $1.09,2.18$ & * \\
\hline Knee & 0.74 & $0.48,1.16$ & \\
\hline Shoulder & 0.60 & $0.35,1.04$ & \\
\hline Elbow & 0.78 & $0.53,1.13$ & \\
\hline Other & 0.84 & $0.56,1.26$ & \\
\hline Multiple & 1.32 & $0.85,2.05$ & \\
\hline$S$ aureus & 0.56 & $0.33,0.95$ & \\
\hline Streptococci & 2.18 & $1.27,3.75$ & $\star$ \\
\hline Other Gram positive & 1.68 & $1.14,2.46$ & * \\
\hline Gram negative & 2.34 & $0.92,5.90$ & \\
\hline H influenzae & 0.53 & $0.33,0.86$ & $\star$ \\
\hline
\end{tabular}

$1 \%(\mathrm{p}>0.05))$; duration of intravenous antibiotic, $4 \%$ and $11 \%(\mathrm{p}>0.05)$; or duration of oral antibiotic, $8 \%$ and $1 \%(\mathrm{p}>0.05)$. For poor outcome the figures are for inappropriate and appropriate: initial treatment, $38 \%$ and $36 \%$ ( $\mathrm{p}>0.05)$; dose of intravenous antibiotic, 34\% and $37 \%(p>0.05)$; duration of intravenous antibiotic, $52 \%$ and $34 \%(\mathrm{p}>0.05)$; dose of oral antibiotic, $38 \%$ and $35 \% \quad(p>0.05)$; and duration of oral dose, $33 \%$ and $35 \%(\mathrm{p}>0.05)$. Thus no discernible effect of the choice or duration of antibiotic on outcome was apparent.

\section{Discussion}

Septic arthritis is an important rheumatological and orthopaedic emergency. Despite this data regarding its clinical features are surprisingly scant. The main virtue of this study is the ascertainment of patients referred to a typical UK health district over a 10 year period regardless of any specific exclusion criteria. In this respect it is similar to previous studies UK studies $^{12}$ although these did exclude some organisms and risk groups. It is also similar to the recent study by Kavanagh and colleagues. ${ }^{7}$ This latter study is, however, biased by its method of case ascertainment as it relied on the spontaneous reporting of septic arthritis through the PHLS Communicable Disease Reporting system. This may have resulted in over-representation of unusual organisms and those associated with bacteraemia. In common with these studies its major drawback is its retrospective nature.

The reliance on the HAI data to identify cases is a problem. Alternative means of ascertainment has allowed some estimate of the number of cases missed (35\%) but this is only possible for some of the period under study. There is no a priori reason to suppose that this would have biased the results although we cannot exclude this possibility. Failure to obtain case-records is not a major problem with this study as we obtained over $95 \%$ of all case records. Finally the use of specific rather than sensitive criteria for septic arthritis means that patients may have been misclassified. This is particularly true of those patients who did not undergo joint aspiration as well as those patients who had pus aspirated while taking antibiotics but who in reality were probably suffering from an inflammatory or crystal related arthropathy. The number of such patients is unclear and their exclusion probably does not significantly change the conclusions obtained.

Prospective studies have now been reported from Amsterdam both using a reporting system in the community ${ }^{3}$ and for a cohort of patients with rheumatic disorders. ${ }^{12}$ These give broadly similar results for the spectrum of organisms seen. The incidence of septic arthritis in this study was 5.7 cases per 100000 inhabitants per year with again a very increased incidence in rheumatoid arthritis.

This study suggests that the main features of septic arthritis are as previously demonstrated. ${ }^{1-5}$ In particular the age groups and joints affected as well as the risk factors are 
confirmed. However, there has been a change in the nature of the pathogens involved over the past 20 years with penicillin sensitive $S$ aureus now a rarity. It should, however, be noted that in keeping with previous studies and teaching $74 \%$ of cases were attributable to $S$ aureus and Streptococci. H influenzae type $\mathrm{b}$ was an important pathogen in children as demonstrated in this series but with the recent successful introduction of the specific vaccine a marked decline in its incidence in invasive disease has already been demonstrated. ${ }^{13}$ The incidence of gonococcal arthritis is much lower than in a previous UK survey ${ }^{2}$ and in accord with a recent study also from Europe. ${ }^{3}$ This continues to be in contrast with reports from urban areas of North America ${ }^{14}$ and tropical Australia $^{4}$ and the reason for this difference remains unclear, but may be because of different circulating serotypes. ${ }^{15}$

These data strongly support the need to obtain synovial fluid before the commencement of antibiotic treatment and also emphasise the importance of an immediate Gram stain of the fluid obtained. However, it is also clear that blood cultures also contribute to the diagnosis and should not be omitted. Overreliance on other features such as the white cell count, temperature, and ESR may be misplaced. The measurement of CRP may be a more sensitive indicator of possible septic arthritis. This study also re-emphasises that multiple joints are not uncommonly affected ${ }^{2-5}$ and that sepsis must still be considered in a patient presenting with multiple hot joints.

The association between delay in diagnosis and increased morbidity has been noted before. ${ }^{12}$ It emphasises the need to maintain a high index of suspicion for the condition, particularly in at risk groups. Early referral and assessment is to be emphasised.

This study also suggests that antibiotic treatment was not always used appropriately. It is difficult to draw firm conclusions from retrospective treatment but the wide variation in doses, variations and agents used would seem difficult to rationalise. Even when antibiotics were given it is difficult to understand why, what might be considered by many to be inadequate doses were used for such a potentially serious condition. It is surprising, however, that an inappropriate use of antibiotic was not associated with a poorer outcome although this may reflect the small numbers of patients involved, their heterogeneous nature and the predominance of other risk factors for poor outcome.

This study emphasises the continuing role of Gram positive infections in septic arthritis, it is therefore important that antibiotic treatment regimens are effective against Gram positive organisms and therefore should be based on a b-lactamase stable penicillin such as flucloxacillin. The addition of an agent with Gram negative activity such as second or third generation cephalosporin should be considered in the elderly, immunocompromised, or in young children, particularly those who have not had the Hib vaccine. Treatment should be modified in light of the Gram stain and culture results.

The suspicion that surgical intervention may be associated with poor outcome is not new. ${ }^{16}$ Again a major difficulty with interpreting this, results from the retrospective nature of these data. It is of course conceivable that early surgical intervention was used for the worst cases, those with a presumed poorer prognosis. However, even in apparently young fit adults with no other adverse risk factors (immunosuppression, trauma, pre-existing arthritis) this increase in poor outcome was still observed with open surgery. It may be that arthroscopy is not associated with poor outcome although the selection of patients for and timing of such intervention is still unclear. Although it is difficult to perform a randomised controlled trial in what remains a relatively rare disease that presents to many specialties and that involves surgical intervention in one arm, the need for further evidence for the benefit of various surgical interventions remains. ${ }^{17}$

We are extremely grateful to all the medical staff in Nottingham for allowing us to review the notes of patients under their care. We are also grateful to Mrs B Eggington, and all the staff of the audit offices at $\mathrm{CHN}$ and $\mathrm{QMC}$ for their invaluable help in identifying and obtaining patient notes, and to Mr D Woodcock, information analyst at District Headquarters for providing demographic details of the Nottingham Health Authority.

1 Newman JH. Review of septic arthritis throughout the antibiotic era. Ann Rheum Dis 1976;35:198-205.

2 Cooper C, Cawley MID. Bacterial arthritis in an English health district; a 10 year review. Ann Rheum Dis 1986 45:458-63

3 Kaandorp CJE, Dinant HJ, van de Laar MAFJ, Bernelot Moens HJ, Prins APA, Dijkamans BAC. Incidence and sources of native and prosthetic joint infection: a community based prospective survey. Ann Rheum Dis 1997;56: $470-5$.

4 Morgan DS, Fisher D, Merianos A, Currie BJ. An 18 year clinical review of septic arthritis from tropical Australia. Epidemiol Infect 1996;117:423-8.

5 Peters RHJ, Rasker JJ, Jacobs JWG, Prevo RL, Karthaus RP. Bacterial arthritis in a district hospital. Clin Rheum 1992; 11:351-5.

6 Kaandorp CJE, Krijnen P, Bernelot Moens HJ, Habbema Kaandorp CJE, Krijnen P, Bernelot Moens HJ, Habbema
JDF, van Schaardenburg D. The outcome of bacterial arthritis. A prospective community-based study. Arthritis arthritis. A prospective

7 Ryan MJ, Kavanagh R, Wall PG, Hazleman BL. Bacterial joint infections in England and Wales: analysis of bacterial solates over a four year period. $\mathrm{Br} \mathrm{J}$ Rheumatol 1997;36:370-3.

8 Joint working group of the British Society for Rheumatology and the Research Unit of the Royal College of Physicians. Guidelines and a proposed audit protocol for the initial management of an acute hot joint. J R Coll Physicians Lond 1992;26:83-5.

9 Syrogiannopoulos GA, Nelson JD. Duration of antimicrobial therapy for acute suppurative osteoarticular infection. Lancet 1988;219:37-40

10 O'Grady F, Finch RG, Lambert HP, Greenwood D. Antibiotic and chemotherapy: Anti-infective agents and their use in therapy. 7th ed. Edinburgh: Churchill Livingstone, 1997.

11 Black J, Hunt TL, Godley PJ, Matthew E. Oral antimicrobial therapy for adults with osteomyelitis or septic arthritis. J Infect Dis 1987;155:968-72.

12 Kaandorp CJE, van Schaardenburg D, Krijnen P, Habbema JDF, van de Laar MAFJ. Risk factors for septic arthritis in patients with joint disease. Arthritis Rheum 1995;38:181925

13 CDSC. The impact of Haemophilus influenzae immunisation on invasive infection in children. Commun Dis Rep CDR Wkly 1993;3:51

14 Sharp JT, Lidsky MD, Duffy J, Duncan MW. Infectious arthritis. Arch Intern Med 1979;139:1125-30

15 Hook EW. Septic gonococcal arthritis is much more common in the USA than in the UK. Br J Rheumatol 1990;29:283.

16 Goldenberg DL, Brandt KD, Cohen AS, Cathcart ES. Treatment of septic arthritis. Comparison of needle aspiration and surgery as initial modes of joint drainage. Arthritis Rheum 1975;18:83-90.

17 Ho G. Bacterial arthritis. Curr Opin Rheumatol 1993;5: 449-53. 